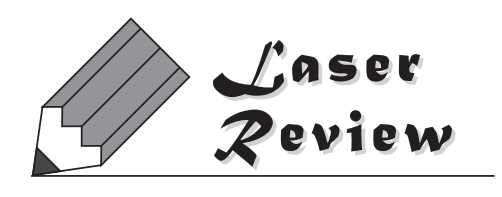

\title{
光配線用1060 nm帯低消費電力VCSEL
}

\author{
喜瀬 智文, 清水均, 那須 秀行 \\ 古河電気工業(株) ファイテル製品事業部門（テ290-8555 千葉県市原市八幡海岸通6）
}

Low-Power Dissipation 1060-nm VCSELs for Optical Interconnect

\author{
Tomofumi KISE, Hitoshi SHIMIZU, and Hideyuki NASU \\ FITEL Products Division, Furukawa Electric Co., Ltd., 6 Yawata-kaigandori, Ichihara, Chiba 290-8555
}

(Received March 20, 2015)

\begin{abstract}
We report the low-power dissipation 1060-nm VCSELs operating at a high modulation speed of $25 \mathrm{~Gb} / \mathrm{s}$ or more. We achieved a direct modulation capability of $25 \mathrm{~Gb} / \mathrm{s}$ with low-power dissipation less than $125 \mathrm{fJ} / \mathrm{bit}$. We also successfully demonstrated $28 \mathrm{~Gb} / \mathrm{s}$ error-free signal transmission at a long distance of $500 \mathrm{~m}$ using an MMF with a modal bandwidth maximized at $1060 \mathrm{~nm}$. An accelerated aging test shows the high reliability of a VCSEL that has an estimated failure rate less than $70 \mathrm{FIT} / \mathrm{ch}$. The 1060-nm VCSEL is a promising light source for future green data centers and high performance computer systems.
\end{abstract}

Key Words: Vertical cavity surface emitting laser, Multimode fiber link

\section{1. はじめに}

近年スマートフォン，クラウドの普及やビッグデータ 活用の進展により，データセンターやスーパーコン ピュータで扱われるデー夕量は飛躍的に増え続けてい る。例えば, スーパーコンピュータの演算速度は4年毎 に10倍のペースで伸びており，2020年にはペタフロップ スの1,000倍の性能をもつエクサフロップのマシンが開 発されることが予測されている 理システムによるエネルギー消費も増大しており，スー パーコンピュータの消費電力は $15 \mathrm{MW}$ 上回る。一般 家庭での平均電力使用量を $400 \mathrm{~W}$ とると, これは約 38,000 世帯分に相当する. 今後のスーパーコンピュータ やデータセンターの進展とともに，システムの消費電力 を抑制することは不可欠となってきている.

情報処理システムの性能向上に貢献する中核技術とし て, 従来の電気配線に代わり，光による配線を実現する 光インターコネクションが急速に普及している. 伝送距 離が数十メートル程度の装置ラック間伝送では, 従来の 電気ケーブルから, 带域や伝送距離に優れ, かつ同一の 電気インターフェースを有するアクティブ光ケーブル (Active Optical Cable: AOC $)^{\dagger 2}$ の置き換えが進んでい
る ${ }^{1,2)}$. 光インターコネクションを実現するレーザー光 源としては, 低消費電力かつ高速並列動作が可能な面発 光レーザー (Vertical Cavity Surface Emitting Laser: VCSEL) が広く採用されている3). AOCには通常10ギガビット イーサネットの短距離用途として広く普及している波長 $850 \mathrm{~nm}$ のVCSELが搭載されている4). 一方, 我々が開発 を行ってきた波長1060 nmのVCSELは, 動作電圧が低 く, 高微分利得のため低バイアス電流での高速動作が可 能といった, 低消費電力の観点からの利点を有している5 .

VCSELおよびそれを用いた光リンクの低消費電力化 は, これまで複数の研究機関による取り組みがなされて

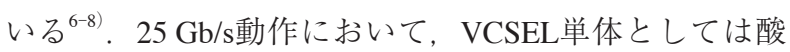
化開口径を $3.5 \mu \mathrm{m}$ と極小化した素子にて $56 \mathrm{fJ} / \mathrm{bit}$ の低消 費電力動作が報告されている ${ }^{6}$ 。但しこの場合, 電流密 度上昇により信頼性に懸念が残る。また, $90 \mathrm{~nm} \mathrm{CMOS}$ (Complementary Metal Oxide Semiconductor) 技術を用いた

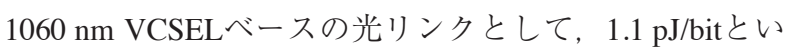
う低消費電力動作も報告されている の高速化の観点では, $100 \mathrm{~Gb} / \mathrm{s}$ 用途ではレーン速度 $25 \mathrm{~Gb} / \mathrm{s}$ の標準化が決まっているが๋3, その先の $400 \mathrm{~Gb} / \mathrm{s}$ の議論も始まっており, レーン速度 $50 \mathrm{~Gb} / \mathrm{s}$ を視野に入 れた検討が行われている

\footnotetext{
${ }^{\dagger 1}$ URL: http://www.top500.org

${ }^{\dagger 2}$ For example, Finisar web page: https://www.finisar.com/active-optical-cables

${ }^{\dagger 3}$ URL: http://www.ieee802.org/3/bm/index.html

${ }^{\dagger 4}$ URL: http://www.ieee802.org/3/bs/index.html
} 
よるVCSEL driverにおいてFFE(Feed-Forward Equalization) 技術により，850 nm VCSELを用いた $71 \mathrm{~Gb} / \mathrm{s}$ の高速動作 が報告されている

我々は，平成23年度から平成 25 年度の間，NEDOの 「省エネルギー革新技術開発事業/先導研究/グリーン光 リンク技術のための低消費電力面発光レーザーアレイの 研究開発」に参画し, スパコン用1060 nm帯低消費電力 VCSELの研究開発を行った。本稿では，その成果を含 めて最新の開発状況について報告する.

\section{2. 低消費電力 $28 \mathrm{~Gb} / \mathrm{s} 1060 \mathrm{~nm}$ VCSEL}

\section{1 基本設計}

$25 \mathrm{~Gb} / \mathrm{s}$ 以上で動作するVCSELの基本設計に当たって は, 高速性, 低消費電力, 高信頼性の全てを同時に達成 することが求められた。検討すべき設計項目としては, 1)活性層構造 (材料)，2）デバイス構造，3)酸化層構造, に大別される。

活性層構造については，高速動作のための微分利得の 向上を目的に，キャリア閉じ込めの観点から障壁層材料 や量子井戸数のパラメータについて, 利得計算等のシ ミュレーションによる検討を実施した。デバイス構造に ついても，高速動作を目的に，主に共振器化の短尺化を 実施した。酸化層の構造設計については，主に注意す心゙ き事項が2点ある。まず，被酸化層はVCSELにおける主 要な寄生容量成分であり，厚膜化することによる容量低 減，および適度な酸化開口径を維持し抵抗上昇を抑える ことにより，RCによる電気的な帯域制限を改善し，高 速動作が実現できる。一方，被酸化層には歪が内在する ため, 特に酸化層が厚くなると歪が蓄積され素子の信頼 性を劣化させる。これらの観点から，酸化層自体の厚さ やメサ径/酸化開口径について構造最適化を行った。

\section{2 素子構造と基本特性}

当社の1060 nm帯VCSELの構造図をFig. 1に示す. GaAs基板上に, $\mathrm{AlGaAs} / \mathrm{GaAs}$ 系の半導体DBR (Distributed Bragg Reflector), InGaAs/GaAs材料を用いた活性層を有 する共振器, 及び誘電体DBRから構成される. 電流狭 窄層は, 高Al組成からなる $\mathrm{AlGaAs}$ 層をメサ側面から水 蒸気により選択的に酸化し, 絶縁体である $\mathrm{AlO}_{\mathrm{x}}$ とした 構造となっており, 中央部の非酸化開口部分を通して電 流が活性領域に注入される。素子構造としては， $\mathrm{P}$ 電

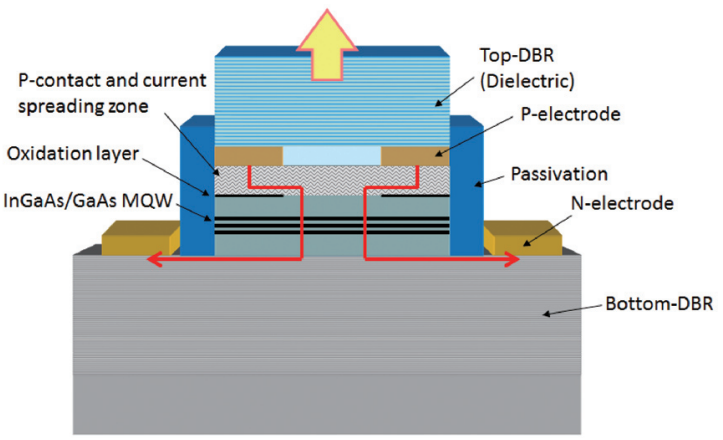

Fig. 1 Device structure of 1060-nm VCSEL.
極， $\mathrm{N}$ 電極共に，共振器内部に配置する構造(イントラ キャビティ構造) となっている。本構造では, 複数の半 導体へテロ障壁を有する半導体DBRには電流が流れな いため，安定した微分抵抗が得られる。また，上部 DBRを誘電体で構成することにより，光学損失を低く 抑えることができ，低しきい值電流動作が可能となる。 このように本構造は低消費電力動作を実現する上でも有 利である。

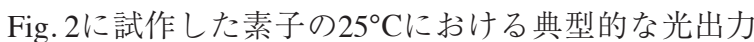
- 電流 - 電圧曲線を示す。酸化開口径は $6 \mu \mathrm{m}$ である. しきい值電流は0.45 mAであり，通常バイアス電流であ る $6 \mathrm{~mA}$ 時の動作電圧も $2 \mathrm{~V}$ 以下と低く抑えられている.

\section{3 高速 ·低消費電力動作}

$25 \mathrm{~Gb} / \mathrm{s}$ 以上の高速動作のためには, 変調周波数帯域 の向上が必要である。一般的に半導体レーザーの周波数 応答は, 電気応答と光学応答の積で表され, 両者の改善 が必要である。電気応答はFig. 3に示すレーザー素子の 等価回路によって決定される， $R_{\mathrm{m}}, R_{\mathrm{j}}$ はメサ部，接合部 の抵抗， $C_{\mathrm{m}}, C_{\mathrm{p}}$ はメサ部, パッド部の寄生容量をそれ ぞれ表している，前述の通り主に酸化層における寄生容 量を低減することが有効であり，酸化層厚さとメサ径/ 酸化開口径の最適化を行った。一方，光学応答はレー ザーのレート方程式を用いて表現され，緩和振動周波数 (Relaxation Oscillation Frequency: $f_{\mathrm{r}}$ ) は式(1)のように表さ れる ${ }^{11)}$.

$$
f_{r}=\frac{1}{2 \pi} \sqrt{\frac{d g}{d n} \frac{v_{g} \eta_{i}\left(I-I_{t h}\right)}{q V_{a}}}
$$

光学応答の改善には, 活性層体積 $\mathrm{V}_{\mathrm{a}}$ の低減および微分

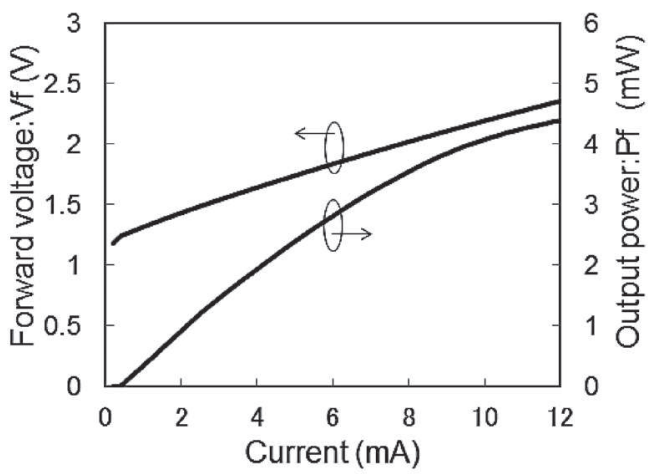

Fig. 2 Light-current and voltage-current characteristics measured at $25^{\circ} \mathrm{C}$.

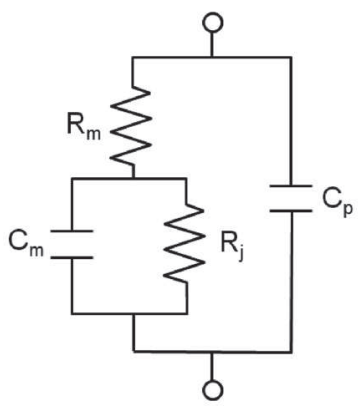

Fig. 3 Equivalent circuit model of the VCSEL. 
利得 $d g / d n$ の増加による $f_{\mathrm{r}}$ の改善が必要である。具体的な 施策として，1)狭酸化開口径化，2) 短共振器化，3)活性 層構造変更による微分利得増加，を実施した。特に短共 振器化は有効であるが, イントラキャビティ構造の場 合, 横方向の電流拡散層が薄くなるため抵抗増加につな がる。これを抑制するため不純物ドーピング濃度の最適 化が重要となる。

Fig. 4に各バイアス電流での $f_{\mathrm{r}}$ を示す。横軸はバイアス 電流としきい值電流の差分の二乗根で示している。 この グラフの傾きを表すD-ファクタは $10 \mathrm{GHz} /(\mathrm{mA})^{1 / 2}$ と高い 值が得られた。周波数応答特性をFig. 5 に示す。実験的 に3dB変調帯域を評価した結果, $3 \mathrm{~mA}$ 時に $15 \mathrm{GHz}$, $5 \mathrm{~mA}$ 時に17 GHzがそれぞれ得られた。

次に，低消費電力動作の検証のため，室温において，

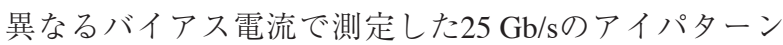
をFig. 6に示す ${ }^{12)}$ 。酸化開口径は5 $\mu \mathrm{m}$ である。低電流駆 動状態について確認した結果， $2 \mathrm{~mA}$ 時でもアイ開口が 得られた. $3 \mathrm{~mA}$ 時においては, $5 \mathrm{~mA}$ 遜色無い十分な アイ開口が得られていることが分かる。 ここでビットあ たりの消費電力 (Power Dissipation)を,

$$
\left(I \times V-P_{0}\right) / \text { bit rate }
$$

と定義する。 $P_{0}$ は光出力である。消費電力は, Fig. 6中 に記した通り， $2 \mathrm{~mA}$ 時に $77 \mathrm{fJ} / \mathrm{bit}(0.077 \mathrm{~mW} / \mathrm{Gb} / \mathrm{s}), 3 \mathrm{~mA}$ 時に $125 \mathrm{fJ} / \mathrm{bit}(0.125 \mathrm{~mW} / \mathrm{Gb} / \mathrm{s})$ と算出された。目標とし

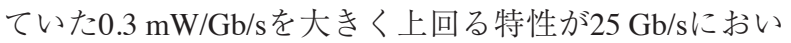
て実現された。消光比も $4 \sim 5 \mathrm{~dB}$ が得られた。後述する ように高信頼性も実現可能な上記素子設計において, $1060 \mathrm{~nm}$ VCSELの優位性のひとつである低消費電力動作

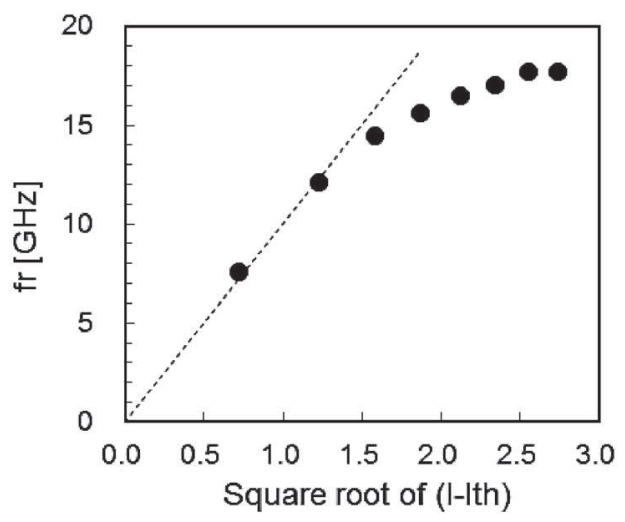

Fig. $4 f_{r}$ plot vs square root of $\left(I-I_{t h}\right)$.

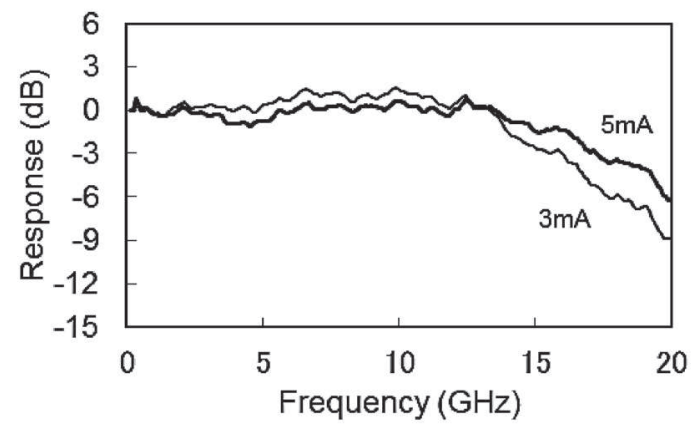

Fig. 5 Frequency response at $3 \mathrm{~mA}$ and $5 \mathrm{~mA}$.

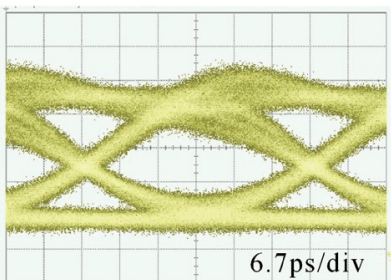

(a)

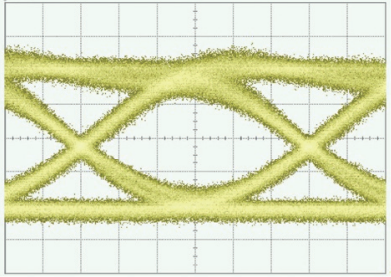

(c)

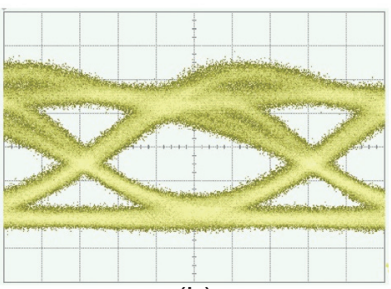

(b)

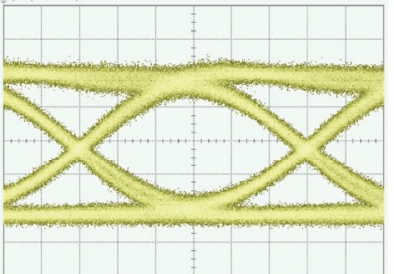

(d)
Fig. $625 \mathrm{~Gb} / \mathrm{s}$ eye diagrams at different bias currents. Estimated power dissipations and measured extinction ratios are indicated at each bias current. (a) $2 \mathrm{~mA}, 77 \mathrm{fJ} / \mathrm{bit}, 5.6 \mathrm{~dB}$. (b) $2.5 \mathrm{~mA}, 100 \mathrm{fJ} / \mathrm{bit}$, $4.9 \mathrm{~dB}$. (c) $3 \mathrm{~mA}, 125 \mathrm{fJ} / \mathrm{bit}, 4.4 \mathrm{~dB}$. (d) $5 \mathrm{~mA}$, $250 \mathrm{fJ} / \mathrm{bit}, 3.7 \mathrm{~dB}$

が検証できたと考えられる。ささらに，より高速の $28 \mathrm{~Gb} / \mathrm{s}$

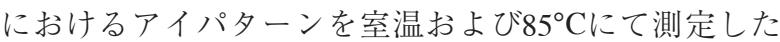

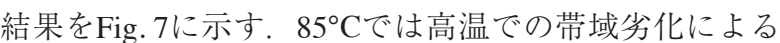
僅かなアイ開口の劣化が見られるが，いずれの温度にお いてもクリアなアイ開口が観測された。

\section{1060 nm VCSELによるマルチモード伝送}

次に1060 nmに最適化したマルチモードファイバ (Multimode fiber: MMF) を用いた伝送実験について報告 する ${ }^{13)}$ ＭMFを用いた光信号伝送において，伝送距離 は，主にモード分散と波長分散によって制限される。 モード分散については，これまでに標準化されている MMFでは，波長850 nmでモード分散が最小になるよう に設計されており，実効モード帯域(Effective Modal Bandwidth: EMB)の規格により，OM2，OM3，OM4に分 類される。従って，850 nmと異なる波長で伝送した場 合，モード分散の影響で伝送特性は大きく劣化する。一 方，石英系光ファイバの波長分散は850 nmから $1060 \mathrm{~nm}$ へと波長が長波長になると, $-90 \mathrm{ps} /(\mathrm{nm} \mathrm{km})$ から $-34 \mathrm{ps} /(\mathrm{nm} \mathrm{km})$ まで減少するため, 長波長の方が長距離 伝送に有利である。そ己で，1060 nm帯において，モー

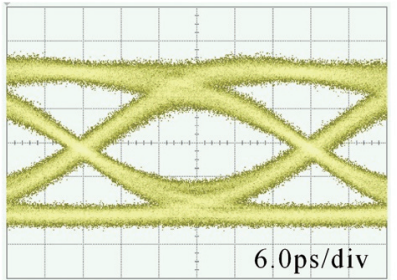

(a)

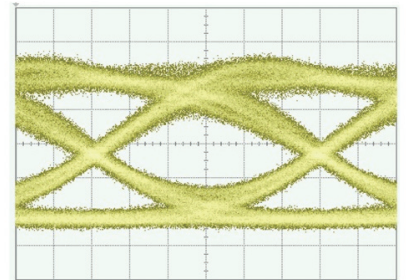

(b)
Fig. $728 \mathrm{~Gb} / \mathrm{s}$ eye diagrams at $25^{\circ} \mathrm{C}$ and $85^{\circ} \mathrm{C}$. Extinction ratio of $4.1 \mathrm{~dB}$ is observed at both temperatures. (a) $25^{\circ} \mathrm{C}, 6 \mathrm{~mA}$. (b) $85^{\circ} \mathrm{C}, 8 \mathrm{~mA}$. 
ド分散が最小化するように設計されたMMFを用いて， VCSELによる光リンクを構成し伝送実験を行った。こ の1060 nm最適化MMFのコア径方向0２3 DMD (differential mode delay) は, 波長1050 nmに招いて $0.12 \mathrm{ps} / \mathrm{m}$ と測定された。これはOM4に相当するモード 分散であることを示している. Fig. 8に伝送実験の測定 系を示す，本実験はVCSELを図中の写真に示す並列光 モジュールに搭載して行った。送信機 $(\mathrm{Tx})$ モジュール にはVCSELアレイとVCSELドライバICが，受信機 $(\mathrm{Rx})$ モジュールにはInGaAs PDとTIAがそれぞれ実装されて いる ${ }^{14)}$. パルスパターンジェネレータ (Pulse Pattern Generator: PPG)SHF12100で発生した $28 \mathrm{~Gb} / \mathrm{s} の \mathrm{NRZ}$, PRBS31段の電気信号をTxモジュールに入力し, VCSEL アレイから出射される信号光がマイクロレンズアレイで 集光しファイバに結合されている。 アイパターン測定時 はファイバをサンプリングオシロスコープAgilent 86105D受信モジュールに接続し，ビットエラーレート (BER) 測定時は, Rxモジュールに接続し, 出力される 電気信号をエラーディテクタ (Error detector: ED)SHF 11102Aで測定を行う。本実験に㧍けるVCSELのバイア ス電流は7.1 mAとした。このバイアス電流に扔けるスペ クトルのRMS線幅は約 $0.5 \mathrm{~nm} ゙$ あった。

Fig. 9に28 Gb/s，PRBS 31段の変調信号を使ったBack to Back㧍よび500 m伝送後のアイパターンを示す。伝送 後はアイ開口が小さくなっているが，500 mまで十分な アイ開口が観測された。また，Fig. $10 に 28 \mathrm{~Gb} / \mathrm{s}$ のBER測 定結果を示す。全ての伝送距離においてエラーフリー伝 送が観測された。ささらに，Fig. 11には $28 \mathrm{~Gb} / \mathrm{s} の B E R$ 測定

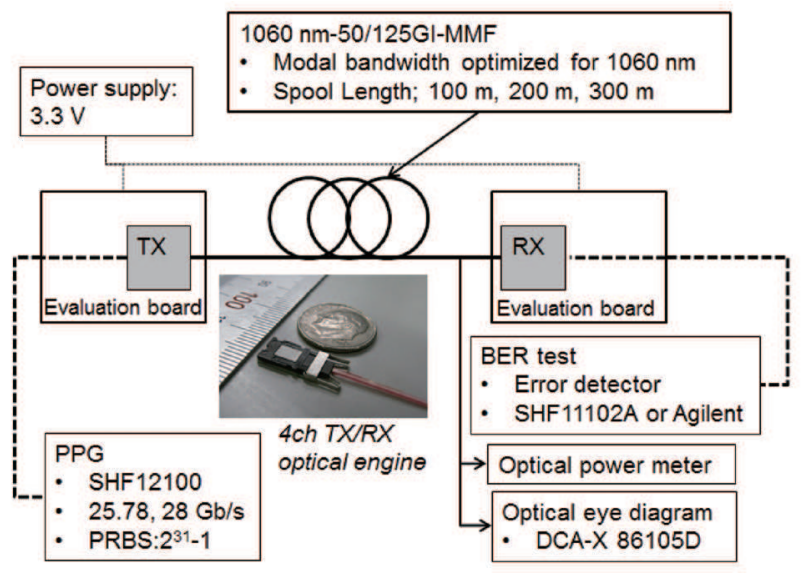

Fig. 8 System setup of transmission test. The inset picture shows a parallel optical transceiver module.

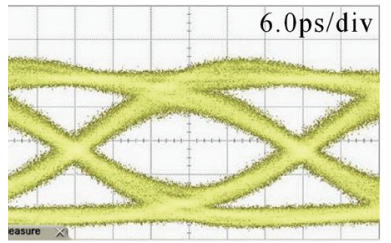

(a)

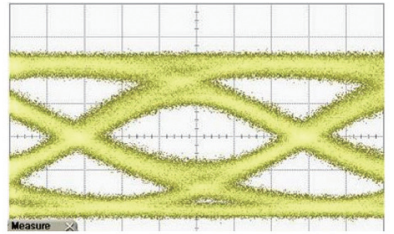

(b)
Fig. $928 \mathrm{~Gb} / \mathrm{s}$ eye diagrams of Back to Back and after $500 \mathrm{~m}$ transmission. (a) Back to Back. (b) After $500 \mathrm{~m}$ transmission.

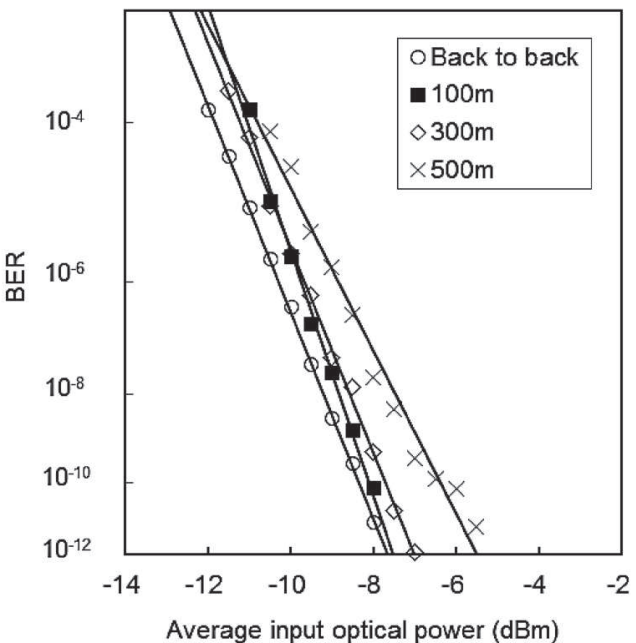

Fig. 10 BER curve of transmission test using MMF optimized for $1060-\mathrm{nm}$ at $28 \mathrm{~Gb} / \mathrm{s}$.

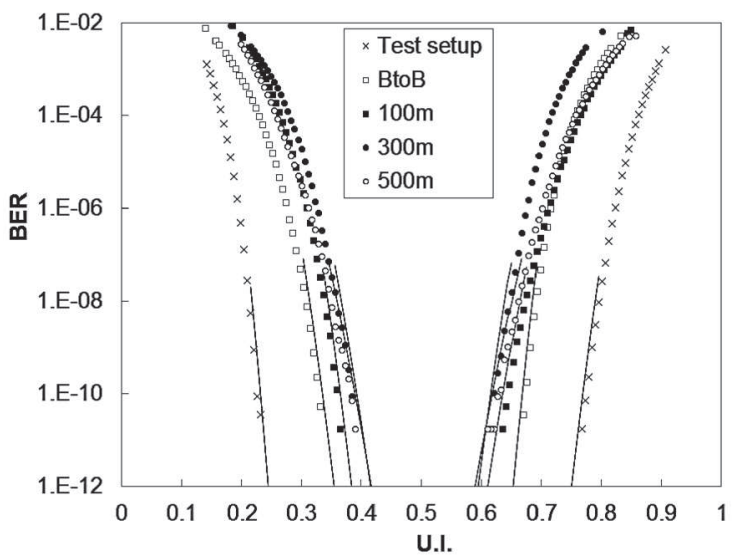

Fig. 11 BER Bathtub curve of transmission test using MMF optimized for 1060-nm.

で得られたジッターバスタブ曲線を示す。 $500 \mathrm{~m}$ 伝送時 のトータルジッタはデュアルディラックモデルを用い て，特性を外挿することにより $0.82 \mathrm{UI}$ と見積もられ， かつジッタマージンがあることを確認した。

\section{4. $1060 \mathrm{~nm}$ VCSELの信頼性}

最後に，試作した素子の信頼性について紹介する. $25 \mathrm{~Gb} / \mathrm{s}$ VCSEL素子の高温での加速通電試験を $120^{\circ} \mathrm{C}$ 16 mAにて実施した。Fig. 12には，バーンインによる初 期スクリーニング後の素子に対する高温加速通電試験結 果の一例を示す。バーンイン条件は，25 Gb/s素子用に 温度および電流密度を最適化した。素子故障の基準は, 通常VCSELの信頼性試験で使用されている光出力の $2 \mathrm{~dB}$ 低下とし，図中に点線で示した。最大で約 3,000 時間の 試験を行っており, 試験素子 2,246 素子中, 故障素子は1 素子であった，加速係数を考慮すると， $5.5 \times 10^{7}$ device hourの試験時間に相当する。実用条件 $\left(40^{\circ} \mathrm{C} / 6 \mathrm{~mA}\right)$ での 偶発故障率として，90\%のC.L. (Confidence Level)におい てchあたり約70 FIT (Failure in Time)が得られ，目標とし ていた100 Fit/ch以下を達成した。この通電時間は，想 


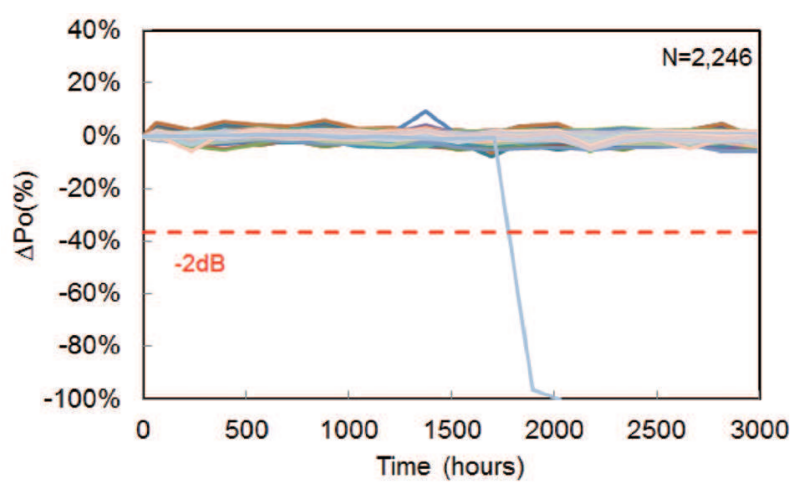

Fig. 12 Accelerated aging test results at $120^{\circ} \mathrm{C} 6 \mathrm{~mA}$.

定される実際の動作環境 $\left(40^{\circ} \mathrm{C}, 6 \mathrm{~mA}\right)$ に換算すると約 48年に相当する (活性化エネルギー $E_{\mathrm{a}}=0.7 \mathrm{eV}$ で換算). 本試験結果から今回開発した $25 \mathrm{~Gb} / \mathrm{s}$ VCSELが実用上十 分な信頼性を有していることが示唆された。

\section{5. まとめ}

本稿では, $25 \mathrm{~Gb} / \mathrm{s}$ 以上で動作する低消費電力 $1060 \mathrm{~nm}$ VCSELは高効率特性を有し, 低電流で駆動できるため, VCSEL単体として $125 \mathrm{fJ} / \mathrm{bit}$ 以下の低消費電力動作を実現 できることを示した。また，1060 nmにモード分散を最 適化したMMFを用いて，28 Gb/sにて500 mまでエラーフ リー伝送を実現した。 現在, データセンターの大規模化 が進み, 光インターコネクションの長距離化が求められ ている ${ }^{15)}$. 本技術は長距離光リンク用途にとっても有望 な技術と言える。また, 信頼性試験を実施した結果, 現 時点で70 FIT/chという故障率が得られ, 高い信頼性を有 することが示唆された。 これらの技術が, 将来の低消費 電力な情報処理システムの発展に貢献することを期待し たい.

\section{謝 辞}

本研究の一部はNEDOの「省エネルギー革新技術開発
事業/先導研究/グリーン光リンク技術のための低消費電 力面発光レーザーアレイの研究開発」より助成を受け た.

\section{参考文献}

1) Quad small form-factor pluggable (QSFP) transceiver specification revision 1.0 Dec. 2006.

2) 那須秀行, 瀬尾浩司：エレクトロニクス実装学会誌 14 (2011) 537.

3) C. Ji, J. Wang, D. Soderstrom, K-L Chen, R. Murty, M. Keever, L. Giovane, J-K Hwang, G-H Koh, J. Tan et al.: Proc. SPIE $\mathbf{7 2 2 9}$ (2009) 722904.

4) P. Westberg, J. S. Gustavsson, A. Haglund, M. Skold, A. Joel, and A. Larsson: IEEE J. Sel. Top. Quantum Electron. 15 (2009) 694.

5) K. Takaki, S. Imai, S. Kamiya, H. Shimizu, Y. Kawakita, K. Hiraiwa, T. Takagi, J. Yoshida, T. Ishikawa, N. Tsukiji, et al.: Proc. SPIE 7952 (2011), 795204.

6) P. Moser, J. A. Lott, P. Wolf, G. Larisch, H. Li, N. N. Ledentsov and D. Bimberg: Electron. Lett. 48 (2012) 1145.

7) S. Imai, K. Takaki, S. Kamiya, H. Shimizu, J. Yoshida, Y. Kawakita, T. Takagi, K. Hiraiwa, T. Suzuki, N. Iwai, et al.: IEEE J. Sel. Top. Quantum Electron. 17 (2011) 1614.

8) Yu-Chia Chang, and Larry A. Coldren: IEEE J. Sel. Top. Quantum Electron. 15 (2009) 704.

9) J. B. Heroux, T. Kise, M. Funabashi, T. Aoki, C. L. Schow, A. V. Rylyakov, and S. Nakagawa: IEEE J. Lightwave Technol. 33 (2015) 733 .

10) D. M. Kuchta, A. V. Rylyakov, F. E. Doany, C. L. Schow, J. E. Proesel, C. W. Baks, P. Westbergh, J. S. Gustavsson, and A. Larsson: IEEE Photon. Technol. Lett. 27 (2015) 577.

11) L. A. Coldren, S. W. Corzine, and M. L. Mashanovitch: Diode Lasers and Photonic Integrated Circuits (John Wiley \& Sons, Inc., 2012) p.203.

12) T. Suzuki, M. Funabashi, H. Shimizu, K. Nagashima, S. Kamiya, and A. Kasukawa: Proc. SPIE 9001 (2014) 900104.

13) T. Kise, T. Suzuki, M. Funabashi, K. Nagashima, R. Lingle, D. S. Vaidya, R. Shubochlin, J. T. Kamino, X. Chen, S. R. Bickham, et al.: Technical Digest of OFC2014 (2014) Th4G.3.

14) H. Nasu, K. Nagashima, and Y. Ishikawa: IEEE J. Lightwave Technol. 31 (2013) 4111.

15) X. Chen, S. R. Bickham, H-F Liu, O. I. Dosunmu, J. E. Hurley, and M-J Li: Technical Digest of ECOC 2013 (2013) PD-4-F5. 